\title{
Employment as a Health Determinant for Working-age, Dually-eligible People with Disabilities
}

\author{
Jean P. Hall, $\mathrm{PhD}$ * \\ Noelle K. Kurth, MS \\ Institute for Health and Disability Policy Studies \\ University of Kansas
}

Suzanne L. Hunt, MS, MA

Department of Biostatistics

University of Kansas Medical Center

* corresponding author

Jean P. Hall

J.R. Pearson Hall, Room 517

1122 West Campus Road

Lawrence, KS 66045-3101

Phone: 785-864-7083

Email: jhall@ku.edu

Published in: 2013, Disability and Health Journal, [online first]. DOI:

10.1016/j.dhjo.2012.11.001

Acknowledgement

The contents of this article were developed under a contract with the Kansas Department of Health and Environment (KHPA2007-055) and a grant from the U.S. Department of Education, NIDRR grant number H133G10082-11. However, contents do not necessarily reflect the policy of the Department of Education, and you should not assume endorsement by the Federal Government.

This paper was presented as Employment as a Health Determinant in a Younger, Dually-Eligible Population at AcademyHealth Disability Research Interest Group meeting, Orlando, FL, June 23, 2012.

Abstract word count: 249

Manuscript word count: 4024

Number of references: 36

Number of figures/tables: 6

Key Words: disability, employment, health disparity, dual-eligible 


\begin{abstract}
Background: Individuals with disabilities are a health disparity population with high rates of risk factors, lower overall health status, and greater health care costs. The interacting effect of employment, health and disability has not been reported in the research.
\end{abstract}

Objective: This study examined the relationship of employment to health and quality of life among people with disabilities.

Methods: Self-reported survey data and secondary claims data analyses of 810 Kansans ages 18 to 64 with disabilities who were dually-eligible for Medicare and Medicaid; $49 \%$ were employed, with 94\% working less than 40 hours per week. Statistical analyses included ANOVA for differences between the employed and unemployed groups' health status, risk scores, and disease burdens; chi-square analyses for differences in prevalence of health risk behaviors and differences in quality of life by employment status; and logistic regression with health status measures to determine factors associated with higher than average physical and mental health status.

Results: Findings indicated participants with any level of paid employment had significantly lower rates of smoking and better quality of life; self-reported health status was significantly higher, while per person per month Medicaid expenditures were less. Employment, even at low levels, was associated with better health and health behaviors as well as lower costs. Participants reported being discouraged from working by medical professionals and federal disability policies.

Conclusions: Although cause-effect cannot be established from this study, findings strongly support changes to provider practices and federal disability policy to support employment at all levels for people with disabilities. 


\section{Introduction}

Working age individuals with disabilities are a health disparity population, having much higher rates of smoking and obesity and lower rates of dental care visits and medical screening services, such as mammograms, than do their peers without disabilities. (1) These individuals are also more likely to be in fair to poor health, to experience serious psychological distress and comorbid health conditions, and to have lower income and higher rates of unemployment. $(2,3)$ Indeed, working age people with disabilities are 2.8 times more likely to live in poverty than those without disabilities. (2) In turn, lower financial status puts people with disabilities at risk for living in substandard housing and for social and environmental risks that negatively affect health, such as exposure to violence and not having access to health promotion activities. Moreover, these health disparities are present across all disability groups, such as sensory, mobility/physical, psychiatric, and intellectual. (4)

Although a large body of research exists on the relationship of income and health, much less research examines the specific and interacting effects of employment, health and disability. $(5,6,7,8)$ As Ross and Mirowsky noted, “employment correlates positively with health, but is employment cause or consequence?” (9) Indeed, researchers have historically argued that much of the correlation between employment and health is due to the selection of healthy people into the workforce. $(10,11,12)$ Acknowledging the confounding nature of the relationship, Ross and Mirowsky found that economic well-being from earned wages accounted for only a small portion of employment's effect on changes in health, indicating that even lower income jobs might result in improved health status. (9) On the other hand, work has also been associated with poorer health outcomes when workplace conditions are not optimal. $(13,14,15)$ In its report on social determinants of health, the World Health Organization noted that stress in the workplace plays 
an important role in health. (16) The report suggested that having low decision-making authority or control over one's work is particularly predictive of adverse health outcomes for employees.

Very few studies have examined the effect of employment on health and quality of life outcomes specifically among people with disabilities. A few small studies have investigated the effect of paid employment on quality of life, self-esteem and mental health among people with severe mental illness. $(17,18,19,20)$ All but one of these studies found significant improvements in these domains for workers compared to non-workers with the same conditions. Further, studies of vocational rehabilitation (VR) outcomes have shown people with mental illness who obtain employment through VR also have higher levels of self-esteem and fewer symptoms than those who do not work. $(19,21)$ Studies of people with mental illness have indicated that even low levels of work can have clinical benefits and contribute to improved overall mental health. $(17,18,20)$ Similarly, other studies found that employment was associated with greater quality of life for people with physical disabilities and intellectual disabilities. $(22,23)$

Yet, people with disabilities have historically been served by state and federal programs that require them to remain poor, and therefore unemployed, in order to get the health care services they need. The Balanced Budget Act of 1997 (P.L.105-33) and the Ticket to Work and Work Incentives Improvement Act of 1999 (TWWIIA) (P.L. 106-179) allowed states to create Medicaid Buy-In programs that enable people with disabilities to work and increase income without losing Medicaid benefits. Although the stated intention of these programs is to reduce this population's dependency on federal cash benefits, the potential exists for people with disabilities enrolled in Buy-Ins to begin or continue to work, increase income and savings, improve health status, increase independence and decrease medical expenditures. Medicaid BuyIn programs currently operate in 45 states. 
Because individuals with disabilities eligible for Supplemental Security Income (SSI) can only maintain their Medicaid coverage through the 1619 a and b programs, the majority of BuyIn participants nationally are people who receive Social Security Disability Insurance (SSDI) and are dually-eligible for Medicare and Medicaid. (24) Approximately 90\% of Buy-In participants in Kansas are dually eligible for both Medicaid and Medicare. (25) Mental illnesses are the single most common condition within the dually-eligible population of people with disabilities. (26) Kansas Buy-In participants, like participants nationally, have a wide range of disabilities, with mental illnesses being the most prevalent. In Kansas, overrepresentation of people with mental illnesses may in large part be due to historical program design features. Unlike people with physical and intellectual disabilities, people with mental illnesses in Kansas were not eligible to receive home- and community-based services (HCBS) through a waiver, and therefore were not subject to any loss of services when enrolling in the Buy-In. In 2007, Kansas implemented HCBS-like services for people with physical and intellectual disabilities and representation of those groups in the Buy-In has grown, but people with mental illnesses remain the largest population. Preliminary findings among Kansas Medicaid Buy-In enrollees indicated that participants with all types of disabilities experienced increased levels of mental health, independence, and financial status. Every year since 2003, more than $50 \%$ of participants have reported improvements in these domains as the result of participating in the Buy-In and, consequently, working competitively. (27) On the other hand, some enrollees reported increases in mental and physical stress caused by their work or that their disabilities worsened because of work. We initially hypothesized that Buy-In participation would predict better health outcomes. What we found, instead, was that employment at any level was associated with better health 
status, lower health care costs, and decreased health risk behaviors, regardless of Buy-In participation status.

\section{Methods}

Design. We used a mixed-methods design with both self-reported survey data and secondary claims data for understanding the associations between employment and health and health risk behaviors, and identifying significant differences in these domains between employed and non-employed participants in our study. The University of Kansas Human Subjects

Committee, which is the University's federally recognized institutional review board, approved this study design as well as all informed consent documents and procedures.

Sample. The study population included all enrollees in the Kansas Medicaid Buy-In as of March 2011 who had been enrolled at least three months $(n=1,168)$ and a randomly selected group of dually-eligible Kansas Medicaid recipients ages 18-64 who had never been enrolled in the Buy-In $(n=1,247)$. The 810 individuals who responded to our survey comprised the total study sample.

Survey instrument. The survey contained items related to demographics, current employment status, employment history, quality of life, health status, health risk behaviors and access to healthcare. To measure quality of life we included the 26 items from the World Health Organization Quality of Life instrument (WHOQOL-BREF). Although not a normed measure, the WHOQOL is internationally recognized and widely used as a reliable and short measure of quality of life that provides the added benefit of measuring four separate domains within the larger quality of life construct. Our survey also included the SF-12 (version 1), a scale derived from the SF-36. The SF-12 yields summary scores for physical health (Physical Component Summary; PCS) and mental health (Mental Component Summary; MCS) as well as several 
subscales. In order to allow for in-state and cross-state comparisons, items from the BRFSS related to health risk factors were also used in the survey. In terms of employment status, survey respondents were asked if they had been employed for pay within the past 30 days as well as the duration of their current employment. For analysis purposes, individuals in both groups were considered employed if they had been employed in the last 30 days and had been working for at least one year. This threshold was chosen to ensure individuals were employed during 2010 to correspond to the Medicaid and Medicare claims data for calendar year 2010. Of the overall sample of 810, employment data from the two items was complete for 776 individuals.

Primary data collection. We surveyed the study population between March and June, 2011. The response rate for Buy-In enrollees was $44 \%(n=513)$ and for the non-enrollees was $24 \%(n=297)$, making a total survey sample size of 810 . The difference in response rates between the groups is likely explained by the fact that Buy-In participants were accustomed to receiving an annual survey, while individuals in the non-enrolled group had never received a survey of this type. Moreover, we encountered more difficulties obtaining accurate contact information for the non-enrollees, with many surveys returned as undeliverable and no working telephone number available. Because the survey process may not have been as familiar to nonenrollees, who had not been previously surveyed annually, we sent initial postcards $2-4$ weeks before mailing the survey and reminder postcards 6-8 weeks after in an attempt to increase sample size. (28) All participants received a toll-free phone number for questions, alternate formats or to have the survey read to them. We paid $\$ 10$ stipends to individuals who completed the survey.

To test representativeness, we compared survey responders to non-responders on demographic variables (gender, age, race and ethnicity) and on health risk scores (described 
below). For both the enrollees and non-enrollees, significantly more females responded to the survey (males were $47.7 \%$ of the enrollee survey recipients but only $42.5 \%$ of the responders and $49.2 \%$ of the non-enrollee recipients but only $39.7 \%$ of the responders). Health risk scores were not statistically different between responders and non-responders for either group, indicating that overall health was similar for responders and non-responders, but people with intellectual disabilities were significantly under-represented among the responders to the non-enrollee survey. Again, unfamiliarity with the survey among non-enrollees, their family members, or proxies may have played a larger role in non-response, and this effect seems to have been particularly pronounced for individuals with intellectual disabilities.

Secondary claims data collection. We obtained administrative claims data from the Kansas Medicaid Management Information System (MMIS; Medicaid claims) and the Research Data Assistance Center (ResDAC; Medicare claims) for calendar year 2010 for both groups.

Analyses. We initially planned to analyze survey and claims data to compare the Buy-In population to dually-eligible individuals not enrolled in the Buy-In. Preliminary tests indicated some differences between the groups in distributions of disability type (i.e., a higher rate of mental illnesses in the Buy-In group; a higher rate of intellectual disabilities in the comparison group). Other demographics were comparable with no significant differences between groups except that comparison group members were slightly older. While some non-significant differences existed between the two groups on quality of life and health risk measures, what became obvious was that the differences within in each group were based upon employment status. Although employment is a requirement for participation in the Buy-In, individuals are allowed a six-month grace period to find a new job should they become unemployed. In addition, some participants work only intermittently or seasonally. These facts, in addition, to the fact that 
some survey participants had been enrolled less than a year, resulted in an employment rate of $89 \%$ for the Buy-In group. Conversely, only $14 \%$ of the non-enrollee group was employed. Of the 776 with complete employment data across both Buy-In and non-enrollee groups, $49 \%(n=$ 381) were employed for at least one year and $51 \%(n=395)$ were not.

Therefore, we revised our analytical approach and used ANOVA to test for significant differences between the employed and unemployed groups' health status (SF-12 Mental Component Summary [MCS] and Physical Component Summary [PCS]). We conducted chisquare analyses to determine differences in the prevalence of health risk behaviors, and to test for differences in quality of life by employment status. Additionally, we conducted logistic regression with health status measures (SF-12 MCS and PCS) to determine factors that predict higher than average physical and mental health status, such as gender, race, age and number of hours employed/week.

For the secondary data analyses, we used calendar year 2010 Medicaid and Medicare claims data to calculate per member per month ( $\mathrm{pmpm})$ costs for those in the employed and not employed groups. The calculation included only claims for months in which the beneficiary was Medicaid eligible. All 776 subjects had at least one Medicaid or Medicare claim in the calendar year. Medicaid claims included outpatient medical (doctor, clinic, therapy visits), Home and Community Based Waiver Services (HCBS), mental health capitation monthly rates, inpatient, dental, and prescription drug costs. Medicare claims included outpatient, physician, inpatient, skilled nursing facility, durable medical equipment, and home health costs. We also utilized Medicaid claims to calculate individuals' risk scores and disease burden using the Chronic Illness and Disability Payment System (CDPS 5.3). CDPS methodology uses diagnosis codes from Medicaid claims to describe the health status of enrollees. The method assigns person-level 
risk scores and categorizes diagnoses into 20 major categories. Although these categories cannot provide a complete picture of an individual's disability (e.g., intellectual, mental illness), they can provide a measure of individual health status. (29) Using these data we performed ANOVA tests to assess differences between risk scores and disease burdens (i.e., number of conditions) for the employed and non-employed groups.

\section{Results}

Demographically, the employed and non-employed groups were very similar (Table 1). The employed group had more individuals with mental illness and intellectual disabilities, probably reflecting the overall higher rate of mental illness among the Buy-In participants and a recent outreach effort to individuals with intellectual disabilities. (Note that disability types are self-reported and, when an individual has more than one disability, the open-ended survey item asks that the respondent list their "main" disability first.)

Table 1. Demographics

Employed Not employed $\quad$ Total sample*

\begin{tabular}{lccc}
\hline Gender (female) & $54.3 \%$ & $61.8 \%$ & $58.8 \%$ \\
Mean age in years (SD, range) & $48.3(10.8,20-$ & $51.1(9.4,25-64)$ & $49.8(10.1,20-64)$ \\
& $64)$ & & \\
Race (White) & $89.5 \%$ & $2.5 \%$ & $3.5 \%$ \\
Ethnicity (Hispanic) & $3.9 \%$ & & \\
Self-reported disability type ${ }^{\dagger+\|}$ & & & $29.1 \%$ \\
Mental illness & $35.2 \%$ & $24.8 \%$ & \\
\end{tabular}




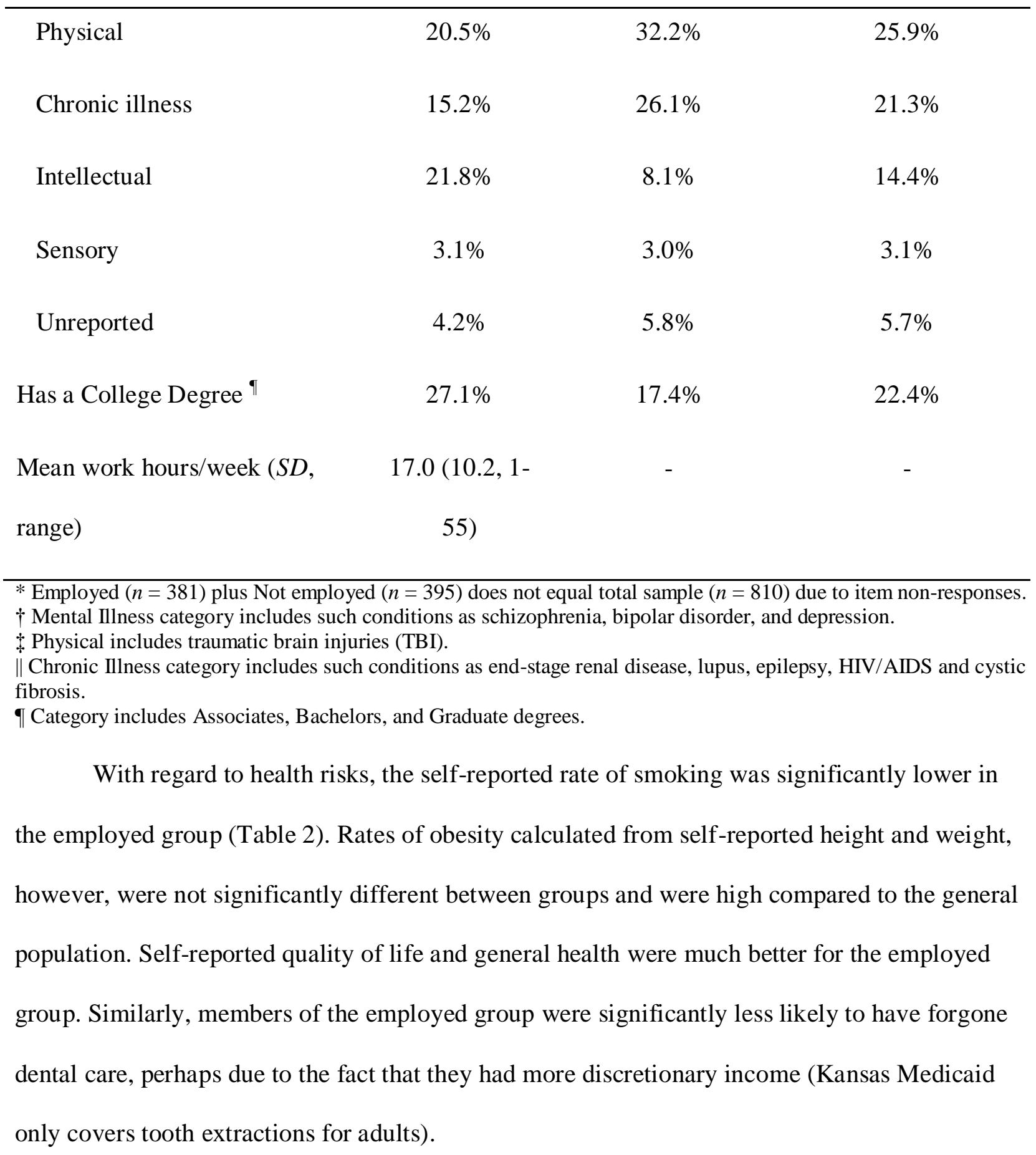


Table 2. Prevalence of Health Risk Behaviors by Employment Status

\begin{tabular}{|c|c|c|c|}
\hline & Employed $^{\dagger}$ & Not employed ${ }^{\dagger}$ & $p$-value \\
\hline Smoking & $25.7 \%$ & $44.8 \%$ & $<.0001 *$ \\
\hline Obesity & $58.0 \%$ & $55.6 \%$ & .283 \\
\hline $\begin{array}{l}\text { Did not get dental care when } \\
\text { needed }^{\ddagger}\end{array}$ & $31.6 \%$ & $43.0 \%$ & $<.001 *$ \\
\hline Report fair or poor health ${ }^{\|}$ & $43.6 \%$ & $65.3 \%$ & $<.0001 *$ \\
\hline Report poor or very poor QOL ${ }^{\mathbb{I I}}$ & $13.1 \%$ & $24.0 \%$ & $<.0001 *$ \\
\hline \multicolumn{4}{|c|}{$\begin{array}{l}* p<.001 \\
\dagger \text { Employed } n=376 \text {; Not employed } n=391 \text {. } \\
\text { t These questions were adapted from the Behavioral Risk Factor Surveillance System (BRFSS): How often do you } \\
\text { smoke cigarettes? and During the past } 12 \text { months, did you not get dental care when you needed it? } \\
\text { |I Item from SF-12: In general, would you say your health is excellent, very good, good, fair or poor? }\end{array}$} \\
\hline
\end{tabular}

Analyses of the physical (PCS) and mental (MCS) health measures in the SF-12 showed significantly higher scores for the employed group (Table 3). Further exploration of the PCS scores using logistic regression found that younger age and male gender were associated with greater odds of having PCS scores above the sample mean of 36.5 (Table 4). Perhaps surprisingly, though, higher levels of education were associated with lower PCS scores. This finding may indicate that individuals with higher educational levels are more aware of and likely to report limitations they experience relative to others. Or, the finding may also indicate that individuals with more sever disabilities have pursued additional education in order to improve their employability. With regard to the effect of employment, the analysis indicated that any level of employment was associated with greater odds of having PCS scores above the mean, 
with more work hours associated with greater odds of higher PCS scores. Finally, people with physical disabilities and chronic illnesses had greater odds of having PCS scores below the mean than did people with intellectual disabilities or mental illnesses. Logistic regression of MCS scores indicated that only gender (female) and disability type (mental illness) were associated with greater odds of scores lower than the sample mean (42.2).

Table 3. Health Status

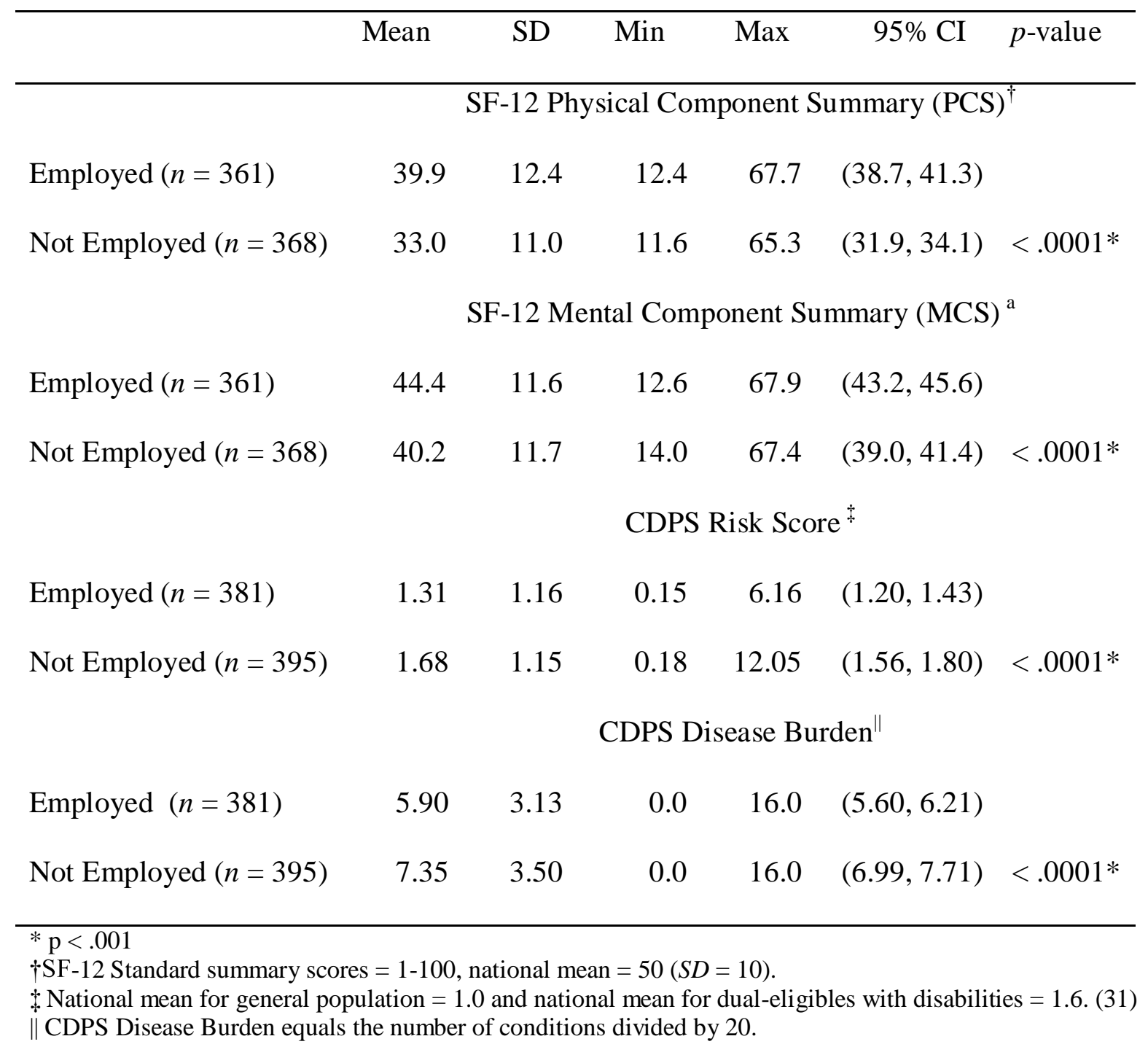


Table 4. Physical Health Logistic Regression

\begin{tabular}{|lcr|}
\hline Variable & Odds Ratio $(95 \%$ CI $)$ & $p$-value \\
\hline Age & $0.964(0.942,0.985)$ & $.0011^{*}$ \\
Gender (female) & $1.693(1.073,2.672)$ & $.0238^{*}$ \\
Education (associates degree+ v. no degree) & $0.554(0.345,0.890)$ & $.0145^{*}$ \\
Employed 11-20 hours/week v. not employed & $2.020(1.138,3.586)$ & $.0163^{*}$ \\
Employed 21-30 hours/week v. not employed & $2.339(1.055,5.186)$ & $.0365^{*}$ \\
Employed 31+ hours/week v. not employed & $4.165(1.590,10.908)$ & $.0037^{*}$ \\
Physical disability v. mental illness & & \\
Intellectual disability v. mental illness & $2.516(0.978,6.470)$ & .0556 \\
\hline Chronic illness v. mental illness & & \\
\end{tabular}

Comparison of CDPS measures of health risk and disease burden (Table 3) showed trends similar to that of the PCS scores, with the employed group having both lower risk scores and fewer chronic conditions than the non-employed group. Similarly, analyses of claims data showed that the employed group had lower overall Medicaid and Medicare costs (Figure 1). Further analysis of expenditure types indicated that the employed group had lower combined outpatient and inpatient medical costs (non-HCBS), with markedly higher inpatient costs among the non-employed group (Figure 2). Looking at only the medical costs indicated in Figure 2 (physician/clinic visits and hospital stays) without any of the HCBS-related costs perhaps 
provides a clearer picture of the health of individuals in these groups. Although HCBS services are vital to independence — and often employment - they do not necessarily correlate with an individual's actual health status.

Figure 1. 2010 Medicare and Medicaid Expenditures (pmpm)

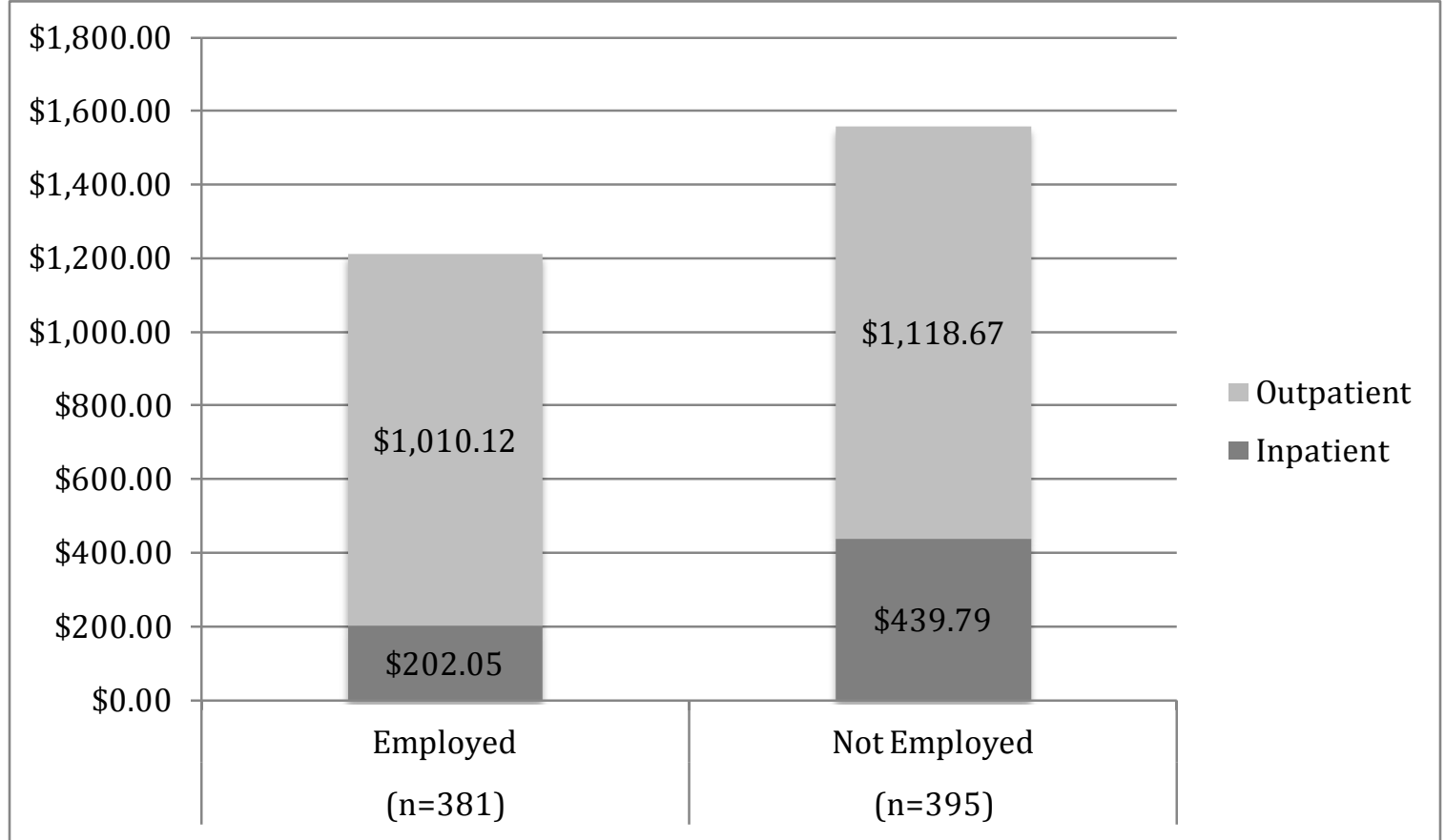

Note: Outpatient claims include medical, mental health capitation rates, targeted case management and HCBSrelated services (dental \& drug claims not included)

Source: Kansas Medicaid Management Information System (MMIS) and CMS Medicare claims data files 
Figure 2. 2010 Medicaid Costs, Medical only (pmpm)

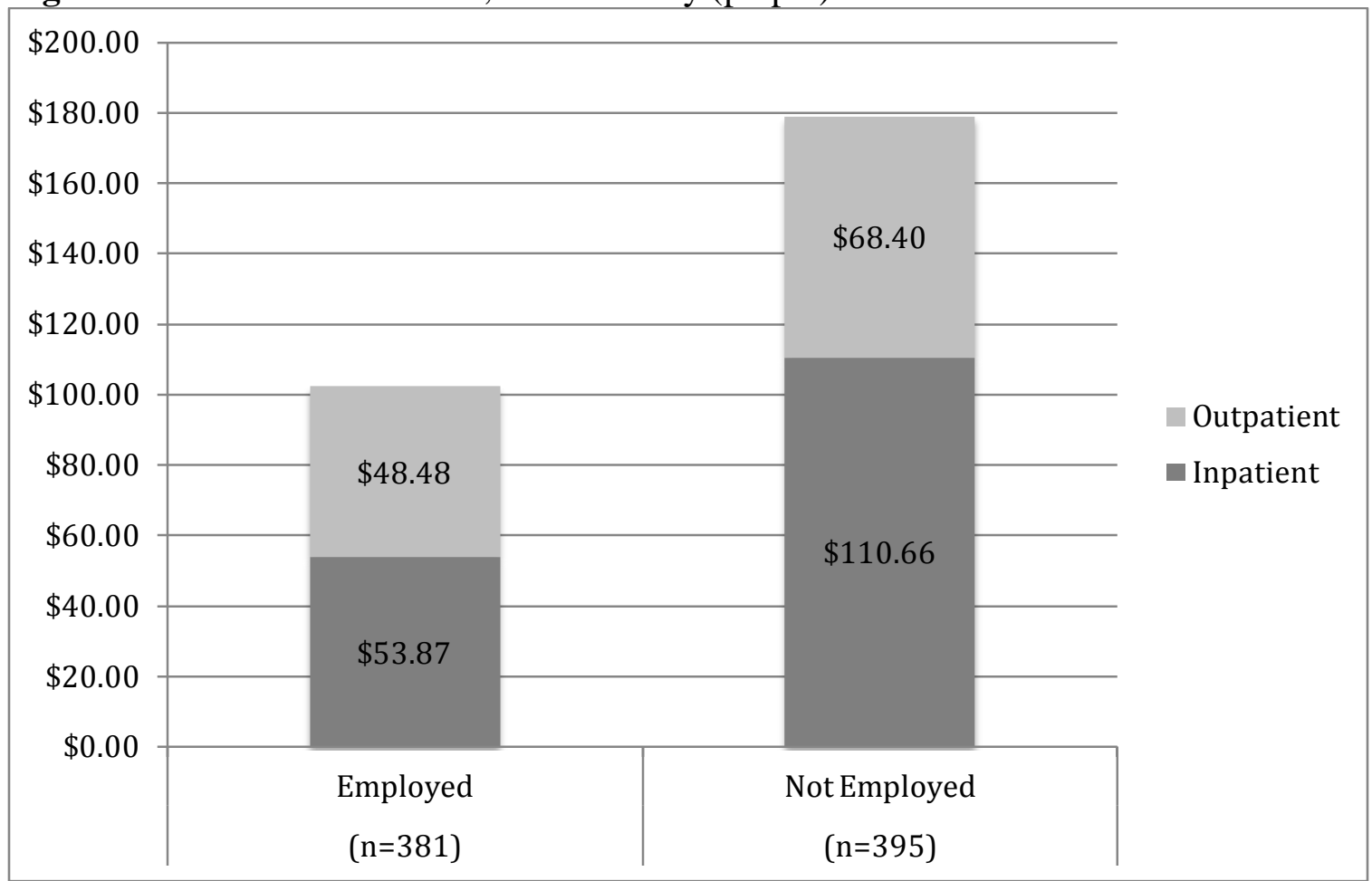

Note: Outpatient medical only claims include doctor \& clinic visits, rehab, physical therapy. Source: Kansas Medicaid Management Information System (MMIS)

\section{Discussion}

Employment showed a positive relationship with all measures of health status - except obesity — and health behaviors across all disability groups. Employment was also associated with lower health care costs to Medicare and Medicaid, a finding of potential national significance given the substantial rise in costs of these programs for people with disabilities. (30) The stark difference in smoking rates between the employed and non-employed groups, alone, has large public health implications. Simply spending time in a workplace that does not allow smoking could account for some of the difference and could have long-term health benefits completely separate from those of the employment itself. Conversely, long-term smokers may be relatively sicker and thus less able to work, a possibility that can perhaps be further explored in future research. Despite our findings, survey participants reported that medical professionals and other 
service providers often discouraged them from working either because they would lose their disability benefits or their disability might worsen. (32) Moreover, recent guidance from the Social Security Administration discourages supporting long-term, part-time employment among federal disability beneficiaries. (33)

Obesity is a national health problem for the entire population. (34) While employment was associated with better health and lower rates of smoking in our population of people with disabilities, it showed no relationship with obesity, with high rates of obesity in both the employed and unemployed groups. Indeed, the problem may be larger than our self-reported data suggest because individuals tend to under-report weight and over-report height. (35) To the extent that the relationship of obesity to education, income and other personal characteristics is complex, employment alone is not likely to significantly reduce obesity for people with disabilities. (36)

Although the findings reported are highly suggestive, we cannot yet demonstrate a cause and effect relationship of employment to improved health. Nevertheless, the findings support efforts to encourage work, even work at low levels, among people with disabilities. Currently a second round of surveys and claims analysis is underway and will provide longitudinal data to better test the hypothesis that employment, even at low levels, can result in improved health for working age individuals with disabilities. In the mean time, the present findings strongly support consideration of changes to provider practices and federal disability policy that encourage and support employment at all levels for people with disabilities. 
References

1. Centers for Disease Control and Prevention. Behavioral Risk Factor Surveillance System (BRFSS): 2010. [data table online] Available from:

http://www.cdc.gov/BRFSS/technical_infodata/surveydata/2010.htm.

2. U.S. Department of Health and Human Services, Public Health Service. Healthy People 2010 progress review: Disability and secondary conditions. Washington, DC: Author; 2006.

3. Iezzoni L, Long-Bellil L. Training physicians about caring for persons with dsiabilities: “Nothing about us without us!” Disabil Health J. 2012;5:136-139.

4. Iezzoni L. Eliminating health and health care disparities among the growing population of people with disabilities. Health Aff. 2011;30(10):1947-1954.

5. Adler N, Singh-Manoux A, Schwartz J, Stewart J, Matthews K, Marmot M. Social status and health: A comparison of British civil servants in Whitehall-II with European- and AfricanAmerican in CARDIA. Soc Sci Med. 2008;66(5):1034-45.

6. Lynch J, Kaplan G, Shema S. Cumulative impact of sustained economic hardship on physical, cognitive, psychological and social functioning. N Engl J Med. 1997;337(26); 1889-95.

7. Marmot M, Smith G, Stansfeld S, et al. Health inequalities among British civil servants: the Whitehall II study. Lancet. 1991;337(8754):1387-93.

8. Wynia K, Middel B, van Dijk J, De Keyser J, Reijneveld S The impact of disabilities on quality of life in people with multiple sclerosis. Mult Scler. 2008;14: 972-80.

9. Ross C, Mirowsky J. Does employment affect health? J Health Soc Behav. 1995;36(3):23043, p. 230. 
10. Repetti R, Matthews K, Waldron I. Employment and women's health: effects of paid employment on women's mental and physical health. Am Psychol. 1989;44(11):1394-1401.

11. Waldron I, Herold J, Dunn D, Staum R. Reciprocal effects of health and labor force participation among women: evidence from two longitudinal studies. J Occup Environ Med. $1982 ; 24(2): 126-32$.

12. Waldron J. Homelessness and the issue of freedom. UCLA Law Review. 1991;39:295-324.

13. Bosma H, Peter R, Siegrist J, \& Marmot M. Two alternative job stress models and the risk of coronary heart disease. Am J Public Health. 1998;88(1):68-74.

14. Peter R, Siegrist J, Hallqvist J, Reuterwall C, Theorell T. Psychosocial work environment and myocardial infarction: improving risk estimation by combining two complementary job stress models in the SHEEP Study. BMJ. 2002;56(4):294-300.

15. Wang J. Perceived work stress and major depressive episodes in a population of employed Canadians over 18 years old. J Nerv Ment Dis. 2004;192(2):160-3.

16. Wilkinson R, Marmot M, editors. Social determinants of health: The solid fact. 2nd ed. Copenhagen Denmark: World Health Organization; 2003.

17. Bell M, Lysaker P, Milstein R. Clinical benefits of paid work activity in schizophrenia. Schizophr Bul. 1996;22:51.

18. Dongen C. Quality of life and self-esteem in working and nonworking persons with mental illnesses. Community Ment Health J. 1996;32(6):535-48.

19. Mueser K, Becker D, Torrey W, Xie H, Bond G, Drake R, Dain B. Work and nonvocational domains of functioning in persons with sever mental illness: a longitudinal analysis. J Nerv Ment Dis. 1997;185(7):419-26. 
20. Bond G, Resnick S. Does competitive employment improve nonvocational outcomes for people with severe mental illness? J Consult Clin Psychol. 2001;69(3):489-501.

21. Bell M, Milstein R, Lysaker P. Pay and participation in work activity: Clinical benefits for clients with schizophrenia. Psychiatr Rehabil J. 1993;17(2):173.

22. Kinney W, Coyle C. Predicting life satisfaction among adults with physical disabilities. Arch Phys Med Rehabil. 1992;73(9):863-869.

23. Kober R, Eggleton I. The effect of different types of employment on quality of life. J Intellect Disabil Res. 2005;49(10):756-760.

24. Davis S, Irey H. How does the Medicaid Buy-In Program relate to other federal efforts to improve access to health coverage for adults with disabilities? (\#2). Washington, DC: Mathematica Policy Research, Inc. 2006.

25. [Author]. Evaluating the Kansas Medicaid Buy-In: Factors influencing enrollment, health care utilization, and work. Disabil Health J. 2010;3(2):99-106.

26. Coughlin T, Waidmann T, Watts MO. Where does the burden lie? Medicaid and Medicare spending for dual eligible beneficiaries (\#7895). Washington, DC: The Kaiser Family Foundation, Kaiser Commission on Medicaid and the Uninsured. 2009

27. [Author]. Working Healthy Data Chartbook, 2nd ed. Lawrence, KS: The University of Kansas, Center for Research on Learning, Division of Adult Studies; 2011.

28. Dillman D. Mail and internet surveys: The tailored design method. New York: John Wiley \& Sons, Inc.; 2000.

29. University of California San Diego. Chronic Illness and Disability Payment System. [online system]. 2012. Available from: http://cdps.ucsd.edu/ 
30. Livermore G, Stapleton D, O'Toole M. Health care costs are a key driver of growth in federal and state assistance to working-age people with disabilities. Health Aff. 2011;30(9):1664-1672.

31. Kronick R, Bella M, Gilmer T, Somers S. The faces of Medicaid II: Recognizing the care needs of people with multiple chronic conditions. Hamilton, NJ: Center for Health Care Strategies Inc.; 2007.

32. [Author]. What providers and Medicaid policymakers need to know about barriers to employment for people with disabilities. J Health Soc Policy. 2004;19(3):37-50.

33. Social Security Administration. Informing beneficiaries of the goals of the ticket program: Employment, benefits reduction and self-sufficiency. 2012. Available from: https://yourtickettowork-uat.maximus.com/c/document_library/get_file?uuid=f6bd4120$\underline{9038-4002-8 b 77-438832 \mathrm{fcce} 31 \& \text { groupId=25544 }}$

34. Finklestein E, Trogdon J, Cohen J, Dietz W. Annual medical spending attributable to obesity: Payer- and service-specific estimates. Health Aff. 2009;28(5):w822-w831.

35. McAdams M, Van Dam R, Hu F. Comparison of self-reported and measured BMI as correlates of disease markers in U.S. adults. Obesity. 2007;15(1):188-196.

36. Ogden C, Lamb M, Carroll M, Flegal K. Obesity and socioeconomic status in adults: United States, 2005-2008. Data Brief No. 50. Washington, DC: U.S. Department of Health and Human Services, National Center for Health Statistics; 2010. 